\title{
The Capabilities Questionnaire for the Community Mental Health Context (CQ-CMH): A Measure Inspired by the Capabilities Approach and Constructed Through Consumer-Researcher Collaboration
}

\author{
Beatrice Sacchetto, Rita Aguiar, \\ Maria João Vargas-Moniz, \\ and Maria Fátima Jorge-Monteiro \\ ISPA-Instituto Universitário
}

\author{
Maria João Neves, Maria Adelaide Cruz, \\ and José António Coimbra \\ Portuguese Network of People With Lived Experience of Mental \\ Illness, Lisbon, Portugal
}

\author{
José Ornelas \\ ISPA-Instituto Universitário
}

\begin{abstract}
Objective: The involvement of people with psychiatric disabilities in research and service evaluation has traditionally been rare, especially in the construction of outcome measures. This study documents a collaborative process with consumers from 2 Portuguese community mental health services in the construction of the Capabilities Questionnaire for the Community Mental Health context (CQ-CMH). The measure is inspired by Nussbaum's capabilities approach and aims to measure consumers' capabilities when supported by the community mental health services. Method: Focus groups with 50 consumers from 2 programs generated data about their gains from and goals for participation in the programs. A Steering Committee-comprising 3 consumers and 2 researchers-analyzed the data, generated a list of items, sorted them according to Nussbaum's list of capabilities, and developed a rating scale. To check face validity, the questionnaire was tested with 15 consumers. Results: The collaborative process led to the transformation of traditional research roles, the promotion of empowerment to participants, the ecological validity of the results, and a cultural adaptation of Nussbaum's list to the context of the study. The resulting CQ-CMH is composed of 104 items organized by 10 capabilities, and 1 open-ended question about service improvements. Conclusions and Implications for Practice: The capabilities approach and the collaborative process undertaken both support the exercise of choice and control by people with psychiatric disabilities. The capabilities measure-constructed by consumersmay be used as an outcome measure in service evaluation. The questionnaire will undergo further testing of its validity and psychometric qualities.
\end{abstract}

Keywords: capabilities approach, collaborative research, community mental health services, consumers' perspective, measure

Supplemental materials: http://dx.doi.org/10.1037/prj0000153.supp

Historically, people with psychiatric disabilities experienced severe social segregation. Social exclusion grievously limits individual opportunities in many life domains, such as education, employment, relationships, and citizenship (Ornelas, Duarte, \& Jorge-Monteiro, 2014). Lack of choice and self-determination has been reproduced at many levels of consumers' lives, including in the involvement in the design and delivery of services to be

This article was published Online First August 31, 2015.

Beatrice Sacchetto, Rita Aguiar, Maria João Vargas-Moniz, and Maria Fátima Jorge-Monteiro, Department of Community Psychology, ISPAInstituto Universitário; Maria João Neves, Maria Adelaide Cruz, and José António Coimbra, Portuguese Network of People With Lived Experience of Mental Illness, Lisbon, Portugal; José Ornelas, Department of Community Psychology, ISPA-Instituto Universitário.

Correspondence concerning this article should be addressed to Beatrice Sacchetto, Rua Jardim do Tabaco, 34, 1149-041, Lisboa, Portugal. E-mail: bsacchetto@ispa.pt received (Chamberlin, 2005) and collaboration in service evaluation and research activities (Jones, Harrison, Aguiar, \& Munro, 2014; Springett \& Wallerstein, 2008).

Accordingly, the present study proposes two ways of overcoming these challenges: the capabilities approach, as a new framework that presents specific guidelines to orient community mental health services and to pursue a recovery mission, and a collaborative approach with the consumers, to guarantee power, control, and access to choice to a historically oppressed population. Thus the twin goals of the present study are (a) the development of a measure based on the capabilities framework, and (b) the establishment of an empowering collaborative partnership between researchers and consumers.

\section{The Capabilities Approach as an Inspiration for the Mental Health System}

The capabilities approach originated as an innovative approach to economic welfare and development through the work 
of Amartya Sen (Sen, 1980). Sen collaborated with the political philosopher Martha Nussbaum in the study of the quality of life (Nussbaum \& Sen, 1993). In their framework, the focus shifted from income to capabilities, which are substantive freedoms, namely, what people can actually $d o$ and $b e$, given their own capacities and the environmental opportunities to which they are exposed. In this sense, capabilities are a combination of both individual and social factors (Sen, 1999), underlining the need for supportive contexts. According to Nussbaum (2000), the capabilities approach represents a basic social minimum that all governments should implement. This perspective points to institutional and social responsibility for removing barriers and creating favorable conditions for the promotion of individual capabilities. The capabilities framework is particularly relevant for groups that face challenges: people in a disadvantaged situation may need more institutional and social support to achieve the same level of capabilities as more advantaged people (Shinn, 2014). Specific attention has been given to the population of people with psychiatric disabilities (Davidson, Ridgway, Wieland, \& O'Connell, 2009; Hopper, 2007; Ware, Hopper, Tugenberg, Dickey, \& Fisher, 2008). In the mental health field, the capabilities theory is consistent with the values and principles of the empowerment and recovery models. The focus of the capabilities approach on people's agency converges with the empowerment values of decision-making power and choice (Rappaport, 1985). For empowerment to occur, consumers need to be active decision makers, choosing which activities to pursue instead of receiving preestablished programs passively (Sen, 1999). The opportunity for consumers to define and lead their recovery processes makes the substantive difference for system change, because it implies a transformation of the professional role. Mental health practitioners should first identify consumers' interests and choices, and then facilitate access to a wide range of socially relevant roles (Hopper, 2007). In fact, recovery is best promoted in natural environments that provide people with the opportunities and resources to carry out significant activities (Davidson et al., 2009).

Whereas Sen (1999) focuses on freedom and agency, Nussbaum (2000) outlines a normative list of human capabilities, including economic, political, social, and civic liberties owed to every citizen in every country. The dimensions proposed in Nussbaum's framework are formulated at a high abstract level, so that every community has the liberty to adapt them to the local context: "each nation must and should describe the capabilities it pursues more concretely, using their own history and tradition as a guide" (Nussbaum, 2011, p. 29).

The capabilities approach has already been applied to elaborate measurements in areas such as health economics and public health (Anand et al., 2009; Lorgelly, Lawson, Fenwick, \& Briggs, 2010), and in the mental health field an operationalization of the capability approach for outcome measurement in clinical studies has been introduced (Simon et al., 2013).

The present study proposes another measure grounded on a collaborative process between researchers and consumers: each phase of the instrument development was pursued with consumers' participation.

\section{The Collaborative Approach to Enhancing Consumers' Agency}

The adoption of a collaborative approach is a key principle of community-based research, because it listens to often-oppressed voices (Rappaport, 1985), and promotes social change (Israel, Eng, Schulz, \& Parker, 2005). A collaborative effort is an empowering process that affects community members-by respecting and valuing their experiential knowledge — as well as the research itself, by producing valid knowledge that attends to community issues (Christens \& Perkins, 2008). In the health field, consumer participation has been considered a vehicle for reducing consumer dependency on health professionals (Minkler \& Wallerstein, 2008). In mental health, consumers have historically endured oppression and dependency on the system. Participation is a fundamental means to emancipate and empower them: it represents an opportunity for consumers to take or share control over the system instead of receiving professional interventions passively (Jones et al., 2014; Lord \& Dufort, 1996). A central challenge in a collaborative approach is the power imbalance between researchers and community members (Carrick, Mitchell, \& Lloyd, 2001). Academic researchers perpetuate the false myth that community members have no resources and abilities that are useful for research development. Professionals often resist collaboration with consumers, fearing the loss of their privilege and position as experts, and this enables them to maintain the control of the research agenda (Ochocka, Janzen, \& Nelson, 2002). Further, disparities in professional and scholarly background, or in time perspective, can lead to misunderstanding, and to a climate of mistrust that hinders collaborative effort (Riger, 2001). To overcome all the existing gaps between groups, a "bridge-building process" needs to be established (Sullivan \& Kelly, 2001, p. 4) to which both academics and consumers contribute their mastery and knowledge. As Boothroyd, Fawcett, and Foster-Fishman (2004) indicated, the articulation of scientific and significance assessment produces knowledge with relevant individual, social, and political impact. Moreover, consumers are often interested and willing to contribute to research activities, because of dissatisfaction and frustration with current clinical and academic research, or because of a desire to see advances in the mental health system (Telford \& Faulkner, 2004).

Beyond participation in research, consumers have the right to be involved in service delivery and evaluation (Chamberlin, 2005; Springett \& Wallerstein, 2008). Nevertheless, recent studies report that even the definition of service outcomes is often not relevant to consumers and is quite different from what they expect from a mental health service (Rose, 2001; Thornicroft \& Tansella, 2010). Moreover, professionals and university researchers have constructed the majority of the existing outcome measures without including consumers' perspectives (Rose et al., 2011). Thornicroft and Tansella (2010) underline the importance of a user-valued measure, in other words, a measure "that reflects the values and experiences of a majority of consumers" (p. 4), especially in the areas of satisfaction, quality of life and service outcome.

Following these arguments, the present study describes a collaborative approach to the construction of the capabilities measure proposed here. 


\section{Method}

\section{Context}

The academic team was composed of five researchers in community psychology, one of them with lived experience of mental health challenges, from the Portuguese ISPA-IU University (ISPAInstituo Universitário). To obtain variability in data about consumers' experiences, two community mental health services in Lisbon were identified: the Association for Study and Psychosocial Integration (AEIPS), a private nonprofit organization whose mission is recovery and community integration (Ornelas et al., 2014); and the Association for Rehabilitation and Social Integration (RECOMEÇO), a community program developed by the psychiatry department of a general hospital that aims for psychosocial rehabilitation and sociooccupational integration.

\section{Study Design}

To pursue the goal of constructing the questionnaire based on consumers' perspectives, the academic team defined a qualitative and collaborative research procedure, composed of the following phases: (a) data collection, through focus groups, about consumers' gains and goals; (b) data analysis, and item and rating scale development by a Steering Committee composed of two researchers from the academic team and three consumers; (c) review and organization of the data based on Nussbaum's capabilities list, by the same Steering Committee; and (d) examination of face validity with the help of 15 consumer volunteers.

Further studies will make use of quantitative methods to produce a well-established measure suitable for community mental health services evaluation.

\section{Procedures}

First phase: Data collection. The aim of the first phase was to gather information about consumers' goals and gains in the community mental health service they were attending. Consumers' aims were considered a key dimension reflecting achievable capabilities, and were later translated into functionings (achieved or functional capabilities) to assess whether consumers gain access to valued activities and roles.

Focus group sessions were conducted, to empower participants' voices and to promote critical reflection (Denzin \& Lincoln, 2005). The criteria for consumers' participation were: at least three months of service utilization and a psychiatric diagnosis. Fifty volunteers participated, 36 from the AEIPS organization, and 14 from the RECOMEÇO service. After signing consent forms, they completed brief questionnaires covering demographic and organizational information. The majority $(70 \%)$ of participants were male, with an average age of 42 years $(S D=8.79)$. At the time of data collection, $14 \%$ were studying, $28 \%$ were working, and the remaining 58\% were involved in other activities at the two programs (e.g., sports activities, or language or computer courses). Each focus group received a worksheet to orient their discussion; this was based on the dimensions identified earlier as being important to recovery and community integration (Nelson, Kloos, \& Ornelas, 2014). ${ }^{1}$ Groups were composed of an average of five consumers and one facilitator to encourage participants' involve- ment (Becker, Israel, \& Allen, 2005), and were heterogeneous with respect to the length of time consumers had used the services, so that people with a long experience could debate with consumers who had joined more recently. Each group selected a note taker who had the task of recording the group's ideas (Krueger, 2006). First, participants discussed the gains they made through participation in the programs. Then they discussed the goals they would like to pursue with the support of the programs. Overall, a total of 11 focus groups were held: eight in the AEIPS organization, and three in the RECOMEÇO service. The academic team collected 11 worksheets with notes of the groups' discussions.

Second phase: Consumer-oriented data analysis, and item and rating scale development. A specific Steering Committee (SC) for the data analysis task was established; this was composed of two members of the academic team and three consumers (two females and one male) intentionally invited to join the panel as experts on their own experiences (van Draanen et al., 2013). The three consumers are leaders of the Portuguese National Network of People with Experience of Mental Illness (Rede Nacional das Pessoas com Experiência de Doença Mental), and actively engage in campaigns for peer support and the representation of peers in conferences/meetings in the mental health area.

The focus group data were transcribed and distributed to all the committee members for a first individual analysis to optimize the group discussion (Israel et al., 2005). In the first meeting, the SC designed three steps for the analysis of the data: the categorization of the data; the selection of the most significant content; and the development of a list of items and a rating scale. For the first task, the data were discussed and organized into categories and subcategories, depending on the contents of the reported gains and goals. Following Barker and Pistrang's (2005) consensus strategy to check the credibility of the data interpretation, the SC discussed the categorization of each group's responses, until agreement was reached. The group discussion also served to clarify the significance of the data, and to combine very similar statements without losing meaning (Becker et al., 2005). In fact, often, testimonies were repeated among different groups. In these cases, the groups' responses were integrated into a unique citation, and the frequency was registered. The same categorizing procedure was pursued for both gains and goals data (see Table 1).

Around 700 responses were categorized by the SC, from which 104 (corresponding to the most frequent of each subcategory) were chosen to constitute the items of the questionnaire. The selected comments were then transformed into critical reflections about individual opportunities provided by the service (e.g., "Participating in this mental health service allowed me to practice more physical activity"; "Participating in this mental health service allowed me to reduce worries about mental illness"). Finally, the SC debated the different options for rating scales, and decided to choose a 5 -point Likert scale $(1=$ totally disagree and $5=$ totally

\footnotetext{
${ }^{1}$ There were six questions for the gains discussion, namely "What kind of gains did you obtain from: education?; employment?; relationships, e.g. with family/friends/other community members?; housing?; participation in service delivery and assessment?; physical health and wellbeing?", and six for the goals discussion regarding the same dimensions: "Which goals do you identify in education?; ..." To identify additional underestimated research topics, an open space was added: "Any gains and goals in other areas?"
} 
Table 1

Examples of Categorization Process for the Focus Group Data

\begin{tabular}{|c|c|c|c|}
\hline Category & Subcategory & Groups' responses & $N$ \\
\hline \multicolumn{4}{|c|}{ "What kind of gains did you obtain in physical health and wellbeing?" } \\
\hline \multirow[t]{2}{*}{ Health } & Physical issues & $\begin{array}{l}\text { G } 1,2,3,5,7,8,10,11 \text { : "To practice more physical } \\
\text { activity." }\end{array}$ & \\
\hline & Mental issues & G 1, 5, 6, 9, 10: "Reduce worries about mental illness." & 5 \\
\hline \multicolumn{4}{|c|}{ "Which goals do you identify in employment?" } \\
\hline Working & $\begin{array}{l}\text { Achievement of new skills } \\
\text { Get a salary }\end{array}$ & $\begin{array}{l}\text { G 2, 4, 6, 9: "To accomplish my commitments." } \\
\text { G 1, 3, 4, 5, 6, 7, 8, 10, 11: "To become financially more } \\
\text { independent." }\end{array}$ & \\
\hline
\end{tabular}

agree) to give consumers a range of responses about accomplished capabilities.

The committee met 20 times to complete these tasks.

Third phase: The capabilities-oriented data review. The goal of the third stage was to develop a capabilities-oriented measure, inspired by Nussbaum's capabilities list (see Nussbaum, 2000 , pp. 78-80). The SC therefore attended a training session: a researcher from the academic team presented the capabilities approach and Nussbaum's list. The list was then translated into Portuguese and used as the interpretive framework (Barker \& Pistrang, 2005) to structure the items logically: each of the 104 items previously chosen was fitted into the most appropriate capability. The matching of the consumers' testimonies collected through the focus groups with Nussbaum's list took 12 meetings. A list of capabilities with specific and adapted definitions resulting from the blending of consumers' testimonies and Nussbaum's original definitions was prepared (see the online supplemental Appendix).

Finally, the consumers who participated in the SC were asked to write down how they felt during the working sessions, that is, how they experienced the collaborative relationship.

Fourth phase: Face validity. To check the acceptability of the measure (Fitzpatrick, Davey, Buxton, \& Jones, 1998), the resulting questionnaire was tested with a group of consumers from the AEIPS organization $(N=15)$, who volunteered for the task. The participants signed consent forms and completed a brief demographic questionnaire. The group was $20 \%$ female, with $43 \%$ between 30 and 39 years of age, and the remainder over 40 . The majority $(58 \%)$ had used the service for more than 10 years, with the rest split between 3 months and 1 year (17\%), 1 and 3 years $(17 \%)$, and 4 and 10 years (8\%). Consumers were invited to share with the group their opinion about the measure-whether the items were comprehensible, the language used, and the importance of the questions addressed.

\section{Results}

\section{The CQ-CMH}

The questionnaire consisted of 104 items ordered by the 10 capabilities and measured on a 5-point Likert scale, which represents the theoretical structure that will be tested in future studies through quantitative methods. A final open-ended question about how community mental health services could better promote con- sumers' capabilities was added to give consumers the opportunity to express their own perspective. Items were developed from the focus group data about consumers' goals and gains. In this sense, the experiences and values of the participants served to define the indicators of capabilities.

The CQ-CMH aims to contribute to the evaluation of community mental health services outcomes, measuring whether consumers are achieving functional capabilities. The achievement of capabilities can be seen as an institutional outcome as well as an individual result, because it reflects the professional endeavor in improving consumers' quality of life. Therefore, the results obtained through a capabilities measure may orient the service delivery, pointing out the strengths and weaknesses of the service, namely in which domains of consumers' lives more support should be provided.

\section{Transformation of Traditional Research Roles}

People with lived experience of mental health challenges have the right to be formally hired as research workers (Delman, 2012; Jones et al., 2014). The academic team therefore employed a person with lived experience of mental health issues under a research contract. Promoting access to employment opportunities in the research field allows the achievement of social justice and equitable status (Ochocka et al., 2002).

For the data analysis task, the SC was composed of two researchers from the academic team and three consumers. Hence the population for whom the research is intended was represented by a majority in the working group. These consumers were chosen on purpose (van Draanen et al., 2013) because of their long experience as consumers/survivors in the mental health system, that is, their personal experience as a unique source of information was being valued.

The SC was an effective group, because all the partners contributed with their skills and competencies to pursue the research goals (Becker et al., 2005). Traditional research roles were changed into more equal relationships. When the consumers on the $\mathrm{SC}$ were asked how they felt during the collaborative working, one said:

Our relationship was one of equal importance and capacity relating to the construction of the questionnaire ... the decisions weren't taken only by the researchers ... the researchers that worked with us heard and accepted many of our suggestions. 
Moreover, the meetings of the SC were always scheduled to accommodate consumers' needs: for instance, breaks were organized during the intensive work of data analysis and review. The communication was clear, open, and adapted to consumers' language, creating a comfortable and trusting climate as well as supportive relationships within the working group (Delman, 2012; Israel et al., 2005).

\section{Empowerment Promotion}

Participation, choice, and power-sharing processes are potential means to promote empowerment (Lord \& Dufort, 1996; Ochocka et al., 2002). One consumer on the SC reflected:

I felt relaxed and that no one was bossing me around . . I I felt that my role was significant because my opinions were taken into account.

These testimonies suggest that professionals were willing to share power and control. Beyond this, formal opportunities for learning and discussion were provided (Ochocka et al., 2002): a formal training session about the capabilities theory was developed, presenting a new perspective for assessing the quality of life, and the total of 32 meetings of the SC allowed the exchange of views and skills, and a process of mutual influence (Rappaport, 1990). Moreover, the collaborative work strengthened individual abilities that were not obvious even to the participants, and that may be useful in the future (Trickett \& Espino, 2004). As one participant on the SC put it:

I learned to work in a team, and felt empowered.

\section{Ecological Validity}

The collaborative approach improves the ecological validity of the knowledge that is produced (Christens \& Perkins, 2008; Trickett \& Espino, 2004). Consumers offered points of view and took initiatives that had a positive impact on the research development. For instance, consumers on the SC often understood better than researchers the meaning of the focus group discussions about, for example, challenges resulting from the experiences of mental health problems and social stigma, or the services needed for support. Their perspective permitted an accurate interpretation of the data. A consumer member of the SC mentioned:

There was a lot about the questionnaire that needed to be improved or replaced in order to make it intelligible and we always had a word in that matter ... the opinion of people with mental illness experience often prevailed. What I mean is that the questionnaire was constructed based on the perspective of the people with mental illness experience.

Consumers' opinions also prevailed in the development of the items, and in the language used. This led to a positive result for the face validity: the 15 participants in that task confirmed their familiarity with the language used, and the relevance of the issues addressed. They also said that the questionnaire was understandable and easy to fill out, although they felt it was too extensive.

\section{Cultural Adaptation of Nussbaum's List}

By creating a capabilities-oriented instrument we are also contributing to the application and measurement of the capabilities approach. Nussbaum's capabilities list was reformulated based on consumers' testimonies and perspectives: the SC developed a proposal of 10 adapted capabilities with specific elements (see the online supplemental Appendix). In this sense, the constructed capabilities list represents what consumers would like to do and to $b e$ in these life domains, or valued activities and roles that they would like to enact with the support of the service. To give an example, we focus on Nussbaum's health capability. To adjust this capability better to the mental health context, the SC chose items that had previously been extracted from the focus group results about both mental and physical health issues, like reducing worries about mental health challenges, and having healthy habits (such as physical activity and healthy eating). Aware that healthy behavior is an important concern for people with psychiatric disabilities, the SC defined the health capability as a combination of states and activities in the pursuit of physical and mental wellbeing.

\section{Conclusion and Implications for Practice}

The article reports on the development of a questionnaire that aims to contribute to the evaluation of the outcomes of community mental health services. The CQ-CMH presents two innovative elements. First, the measure is inspired by the capabilities approach, which focuses on consumers' freedom of choice to be and to do what they value. Nussbaum's list suggests specific dimensions of individual quality of life that should be guaranteed by institutional contexts (Nussbaum, 2000). The capabilities approach offers useful criteria to promote individual capabilities and to evaluate whether program services are recovery-oriented (Davidson et al., 2009; Hopper, 2007; O’Connell \& Davidson, 2010). Finally, "the capabilities approach focuses on ends: what a transformed system should secure to its participants" (Shinn, 2014, p. 83). In this sense, the CQ-CMH is a proposal of what a community mental health service should provide to its consumers. In addition, the present study relied on a qualitative and collaborative process to develop the instrument. Accordingly, the second innovative element is the collaborative approach as a means to promote consumers' choice and agency. By collaborating with consumers on the SC, the academic team carried out a consumer-oriented data analysis (Rose, 2001). When the items of the questionnaire were generated, value was given to the perspective of people who have an understanding of the situation (Thornicroft \& Tansella, 2010). Consumer proficiency needs to be reevaluated as an exclusive source of information about facing mental health challenges and participating in the mental health system (Carrick et al., 2001).

The collaborative approach promotes dimensions that are close to many of the capabilities described by Nussbaum (2000), like practical reason, and control over the environment. To pursue the capabilities mission, mental health professionals need to overcome power imbalances and impaired states (Telford \& Faulkner, 2004) through collaboration with consumers. By integrating the collaborative and the capabilities approaches, we are affirming that the active participation of consumers is a vehicle to foster individual agency and freedom.

Future studies will analyze the psychometric qualities (e.g., reliability and factorial structure) and the validities (e.g., content and construct validity) of the measure. 


\section{References}

Anand, P., Hunter, G., Carter, I., Dowding, K., Guala, F., \& Van Hees, M. (2009). The development of capability indicators. Journal of Human Development and Capabilities, 10, 125-152. http://dx.doi.org/10.1080/ 14649880802675366

Barker, C., \& Pistrang, N. (2005). Quality criteria under methodological pluralism: Implications for conducting and evaluating research. American Journal of Community Psychology, 35, 201-212. http://dx.doi.org/ 10.1007/s10464-005-3398-y

Becker, A., Israel, B., \& Allen, A. (2005). Strategies and techniques for effective group process in CBPR Partnerships. In B. Israel, E. Eng, A. Schulz, \& E. Parker (Eds.), Methods in community-based participatory research for health (pp. 52-72). San Francisco, CA: Jossey-Bass.

Boothroyd, R. I., Fawcett, S. B., \& Foster-Fishman, P. G. (2004). Community development: Enhancing the knowledge base through participatory action research. In L. A. Jason, C. B. Keys, Y. Suarez-Balcazar, R. R. Taylor, \& M. I. Davis (Eds.), Participatory community research: Theories and methods in action (pp. 37-52). Washington, DC: American Psychological Association. http://dx.doi.org/10.1037/10726-002

Carrick, R., Mitchell, A., \& Lloyd, K. (2001). User involvement in research: Power and compromise. Journal of Community \& Applied Social Psychology, 11, 217-225. http://dx.doi.org/10.1002/casp.623

Chamberlin, J. (2005). User/consumer involvement in mental health service delivery. Epidemiologia e Psichiatria Sociale, 14, 10-14. http://dx .doi.org/10.1017/S1121189X00001871

Christens, B., \& Perkins, D. D. (2008). Transdisciplinary, multilevel action research to enhance ecological and psychopolitical validity. Journal of Community Psychology, 36, 214-231. http://dx.doi.org/10.1002/jcop .20232

Davidson, L., Ridgway, P., Wieland, M., \& O'Connell, M. (2009). A capabilities approach to mental health transformation: A conceptual framework for the recovery era. Canadian Journal of Community Mental Health, 28, 35-46. http://dx.doi.org/10.7870/cjcmh-2009-0021

Delman, J. (2012). Participatory action research and young adults with psychiatric disabilities. Psychiatric Rehabilitation Journal, 35, 231-234.

Denzin, N., \& Lincoln, Y. (Eds.). (2005). The Sage handbook of qualitative research (3rd ed.). Thousand Oaks, CA: Sage.

Fitzpatrick, R., Davey, C., Buxton, M. J., \& Jones, D. R. (1998). Evaluating patient-based outcome measures for use in clinical trials. Health Technology Assessment, 2, i-iv, 1-74.

Hopper, K. (2007). Rethinking social recovery in schizophrenia: What a capabilities approach might offer. Social Science \& Medicine, 65, $868-$ 879. http://dx.doi.org/10.1016/j.socscimed.2007.04.012

Israel, B. A., Eng, E., Schulz, A. J., \& Parker, E. A. (2005). Methods in community-based participatory research for health. San Francisco, CA: Jossey-Bass.

Jones, N., Harrison, J., Aguiar, R., \& Munro, L. (2014). Transforming research for transformative change in mental health: Towards the future. In G. Nelson, B. Kloos, \& J. Ornelas (Eds.), Community psychology and community mental health (pp. 351-372). New York, NY: Oxford University Press. http://dx.doi.org/10.1093/acprof:oso/9780199362424.003 .0017

Krueger, R. A. (2006). Analyzing focus group interviews. Journal of Wound, Ostomy, and Continence Nursing, 33, 478-481. http://dx.doi .org/10.1097/00152192-200609000-00004

Lord, J., \& Dufort, F. (1996). Introduction: Power and oppression in mental health. Canadian Journal of Community Mental Health, 15, 5-11. http:// dx.doi.org/10.7870/cjcmh-1996-0007

Lorgelly, P. K., Lawson, K. D., Fenwick, E. A. L., \& Briggs, A. H. (2010). Outcome measurement in economic evaluations of public health interventions: A role for the capability approach? International Journal of Environmental Research and Public Health, 7, 2274-2289. http://dx.doi .org/10.3390/ijerph7052274
Minkler, M., \& Wallerstein, N. (2008). Community-based participatory research for health: From process to outcomes (2nd ed.). San Francisco, CA: Jossey-Bass.

Nelson, G., Kloos, B., \& Ornelas, J. (Eds.). (2014). Community psychology and community mental health. New York, NY: Oxford University Press. http://dx.doi.org/10.1093/acprof:oso/9780199362424.001.0001

Nussbaum, M. (2000). Women and human development: The capabilities approach. New York, NY: Cambridge University Press. http://dx.doi .org/10.1017/CBO9780511841286

Nussbaum, M. (2011). Capabilities, entitlements, rights: Supplementation and critique. Journal of Human Development and Capabilities, 12, 23-37. http://dx.doi.org/10.1080/19452829.2011.541731

Nussbaum, M., \& Sen, A. (Eds.). (1993). The quality of life. Oxford, UK: Oxford University Press. http://dx.doi.org/10.1093/0198287976.001 .0001

Ochocka, J., Janzen, R., \& Nelson, G. (2002). Sharing power and knowledge: Professional and mental health consumer/survivor researchers working together in a participatory action research project. Psychiatric Rehabilitation Journal, 25, 379-387. http://dx.doi.org/10.1037/ h0094999

O'Connell, M. J., \& Davidson, L. (2010). Recovery-oriented care and choice. Psychiatric Services, 61, 845. http://dx.doi.org/10.1176/appi.ps .61.8.845

Ornelas, J., Duarte, T., \& Jorge-Monteiro, M. F. (2014). Transformative organizational change in community mental health. In G. Nelson, B. Kloos, \& J. Ornelas (Eds.), Community psychology and community mental health (pp. 253-277). New York, NY: Oxford University Press. http://dx.doi.org/10.1093/acprof:oso/9780199362424.003.0012

Rappaport, J. (1985). The power of empowerment language. Social Policy, $16,15-21$.

Rappaport, J. (1990). Research methods and the empowerment social agenda. In P. Tolan, C. Keys, F. Chertok, \& L. Jason (Eds.), Researching community psychology: Issues of theory and methods (pp. 51-63). Washington, DC: American Psychological Association. http://dx.doi .org/10.1037/10073-005

Riger, S. (2001). Working together: Challenges in collaborative research. In M. Sullivan \& J. G. Kelly (Eds.), Collaborative research: University and community partnership (pp. 45-60). Washington, DC: American Public Health Association.

Rose, D. (2001). Users' voices: The perspectives of mental health service users on community and hospital care. London, UK: Sainsbury Centre for Mental Health.

Rose, D., Willis, R., Brohan, E., Sartorius, N., Villares, C., Wahlbeck, K., $\&$ the INDIGO Study Group. (2011). Reported stigma and discrimination by people with a diagnosis of schizophrenia. Epidemiology and Psychiatric Sciences, 20, 193-204. http://dx.doi.org/ 10.1017/S2045796011000254

Sen, A. (1980). The welfare basis of real income comparisons: A reply. Journal of Economic Literature, 18, 1547-1552.

Sen, A. (1999). Development as freedom. Oxford, UK: Oxford University Press.

Shinn, M. B. (2014). The capabilities approach to transformative change in mental health. In G. Nelson, B. Kloos, \& J. Ornelas (Eds.), Community psychology and community mental health (pp. 75-86). New York, NY: Oxford University Press. http://dx.doi.org/10.1093/acprof:oso/ 9780199362424.003.0004

Simon, J., Anand, P., Gray, A., Rugkåsa, J., Yeeles, K., \& Burns, T. (2013). Operationalising the capability approach for outcome measurement in mental health research. Social Science \& Medicine, 98, 187196. http://dx.doi.org/10.1016/j.socscimed.2013.09.019

Springett, J., \& Wallerstein, N. (2008). Issues in participatory evaluation. In M. Minkler \& N. Wallerstein (Eds.), Community-based participatory research for health: From process to outcomes (pp. 199-220). San Francisco, CA: Jossey-Bass. 
Sullivan, M., \& Kelly, J. G. (2001). Collaborative research: University and community partnership. Washington, DC: American Public Health Association.

Telford, R., \& Faulkner, A. (2004). Learning about service user involvement in mental health research. Journal of Mental Health (Abingdon, England), 13, 549-559. http://dx.doi.org/10.1080/09638230400017137

Thornicroft, G., \& Tansella, M. (2010). Mental health outcome measures (3rd ed.). London, UK: Royal College of Psychiatrists.

Trickett, E. J., \& Espino, S. L. (2004). Collaboration and social inquiry: Multiple meanings of a construct and its role in creating useful and valid knowledge. American Journal of Community Psychology, 34, 1-69. http://dx.doi.org/10.1023/B:AJCP.0000040146.32749.7d van Draanen, J., Jeyaratnam, J., O'Campo, P., Hwang, S., Harriott, D. Koo, M., \& Stergiopoulos, V. (2013). Meaningful inclusion of consumers in research and service delivery. Psychiatric Rehabilitation Journal, 36, 180-186. http://dx.doi.org/10.1037/prj0000014

Ware, N. C., Hopper, K., Tugenberg, T., Dickey, B., \& Fisher, D. (2008). A theory of social integration as quality of life. Psychiatric Services, 59, 27-33. http://dx.doi.org/10.1176/ps.2008.59.1.27

Received September 17, 2014

Revision received April 28, 2015

Accepted May 7, 2015

\section{Members of Underrepresented Groups: Reviewers for Journal Manuscripts Wanted}

If you are interested in reviewing manuscripts for APA journals, the APA Publications and Communications Board would like to invite your participation. Manuscript reviewers are vital to the publications process. As a reviewer, you would gain valuable experience in publishing. The P\&C Board is particularly interested in encouraging members of underrepresented groups to participate more in this process.

If you are interested in reviewing manuscripts, please write APA Journals at Reviewers@apa.org. Please note the following important points:

- To be selected as a reviewer, you must have published articles in peer-reviewed journals. The experience of publishing provides a reviewer with the basis for preparing a thorough, objective review.

- To be selected, it is critical to be a regular reader of the five to six empirical journals that are most central to the area or journal for which you would like to review. Current knowledge of recently published research provides a reviewer with the knowledge base to evaluate a new submission within the context of existing research.

- To select the appropriate reviewers for each manuscript, the editor needs detailed information. Please include with your letter your vita. In the letter, please identify which APA journal(s) you are interested in, and describe your area of expertise. Be as specific as possible. For example, "social psychology" is not sufficient-you would need to specify "social cognition" or "attitude change" as well.

- Reviewing a manuscript takes time (1-4 hours per manuscript reviewed). If you are selected to review a manuscript, be prepared to invest the necessary time to evaluate the manuscript thoroughly.

APA now has an online video course that provides guidance in reviewing manuscripts. To learn more about the course and to access the video, visit http://www.apa.org/pubs/authors/reviewmanuscript-ce-video.aspx. 